\title{
Investment analysis of Hungarian apple-orchard and fruit storage projects
}

\author{
Apáti, F. ${ }^{1}$ \& Lakner, Z. ${ }^{2}$ \\ ${ }^{1}$ University of Debrecen, Centre of Agricultural Sciences and Engineering, \\ H-4032 Debrecen, Böszörményi str. 138. \\ ${ }^{2}$ Corvinus University Budapesti Faculty of Food Science Department of Food Economics \\ H-1118 Budapest, Villányi str. 29-43.
}

\begin{abstract}
Summary: There are profound, long-term changes in world apple production and trade. The former hegemony of Europe in apple production doest not exists any more, among the most important apple exporters the emerging economies have a growing importance. The globalising apple market means new challenges of traditional producers. This is especially true for Hungary, which has been the most important apple exporter in terms of quantity thirty years ago, but now its production hardly covers the domestic demand. A necessary precondition of the modernisation is the re-construction of plantations and the cold-storage system. Analysing the economic efficiency of apple production and cold storage, it is obvious, that a necessary precondition for the modern, competitive apple production is the availability of cold-storage facilities. Neither the apple-production, nor the cold-storage can not evaluated separately from each other. Under current Hungarian conditions there is a need for active state support for the establishment of cold-storage facilities.
\end{abstract}

Key words: investment, analysis, apple, storage

\section{Introduction}

The fruit production is an important part of the Hungarian agriculture (Takács-György and Vágány, 2003). The valueadded content of fruit-growing is among the highest in portfolio of agricultural production. The fruit growing is a key element of regional development in less favoured areas of Hungary, because it demands a relatively much input of living labour, and in this way offers a favourable possibility for the workplace creation and the utilisation of lesser qualified as well as part-time workers.

In last decades there has been a constant decreasing of fruit production. The most important causes of this process are as follows: (1) relative and absolute decreasing of the intensity of agricultural production; (2) decreasing of technical and technological level; (3) deterioration of biological bases of production. At the same time, there are considerable differences between the different fruitproducing farms. Parallel with the general declining, there are some farms with modern, marketable varieties, intensive plantations, mechanisation and wide-range application of modern production methods and technologies. At the same time, the Hungarian fruit production is far behind from its theoretical agro-ecological potential.

Historically, Hungary had been an important appleproducer and exporter, but its share has been declining in last three decades (Fig. 1). In early 80s of the last century Hungary had been the world's major apple exporter, and the apple exports accounted for 30 percent of the total fruit and vegetable export earnings. Later on this very important position has rapidly changed. The most important causes of these, negative processes have been as follows:

- shrinking export possibilities to the member states of the COMECON countries in the second half of eighties, later on collapse of this market as a consequence of the insolvency and instability of potential buyers;

- increasing market share of EU countries and another, emerging market concurrence, supported by extremely favourable, often state or EU - financed terms of payment;

- high volatility of apple prices on domestic and export market, low level of stability;

- after the shock of the system -changing the Hungarian fruit production sector has reacted to the new situation by a rapid re-configuration of its product portfolio towards the fruit-juice production, but on this market segment it is extremely hard to achieve a strong competitive position, because there is hardly any possibility for the product differentiation, and the more competitive producers (e.g. from Poland or China). 
- obsolete variety structure as well as cultivation practices;

- lack of qualified and easy to motivate living labour;

- low profitability of the Hungarian apple production,

- scattered production structure and product-supply;

- lack of modern storage and logistical facilities.

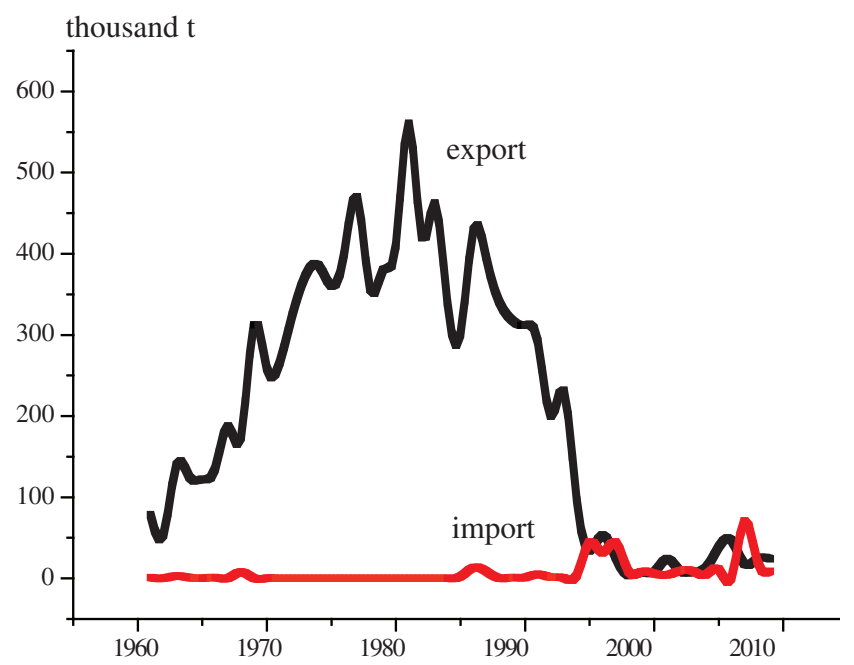

Fig. 1. The Hungarian apple export and import

Source: own calculations, based on electronic database of FAO

With some exaggeration, the Hungarian apple production can be described as the "veterinary horse" of Hungarian horticulture, being able to demonstrate all the problems of the agricultural production. Under these conditions there is an urgent necessity for the restructuration of the Hungarian apple-production, with a specific emphasis on economic feasibility, competitiveness and marketability of products. The establishment of new plantations should be based on a prudent economic analysis. This is especially difficult under conditions of turbulent socio-economic changes. That's why in case of economic analysis of apple-orchard projects, an interplay of different elements of risk should be taken into consideration. The aim of the current paper is to present a comprehensive economic analysis of an apple-orchard project, from the phase of establishment of orchard to the end of the life cycle of it. The structure of article is as follows: the firs part of the study offers an overview of the most important long-range processes on the world apple trade market, in second part the methodology of the research is presented, and the third part of the paper contains an analysis of results as well as some suggestions for the further development.

\section{Transformation of the world apple market}

Analysing time series trends for apple production is difficult because of the considerable annual fluctuations and thus attributing these changes to different economic and policy changes in a relatively short term is difficult and contains a high bias factor. Applying longer time -series it becomes obvious, that there are profound, long-range structural changes in the world apple market.
Traditionally, this market has been dominated by the European countries. In the sixties of the last century more than two-third of the world market production has been grown in the Europe. Total share of Europe and Northern America in world apple production half a century ago had been more than $80 \%$. In the first decade of the third millennium the joint share of Europe and Northern America in the world apple production had not achieved of one third of the total world production. The European apple production can be characterised by a decreasing tendency. As it is obvious, it can be approximated $\left(\mathrm{r}^{2}=0.57\right)$ by a second-order polinom (Fig. 2).

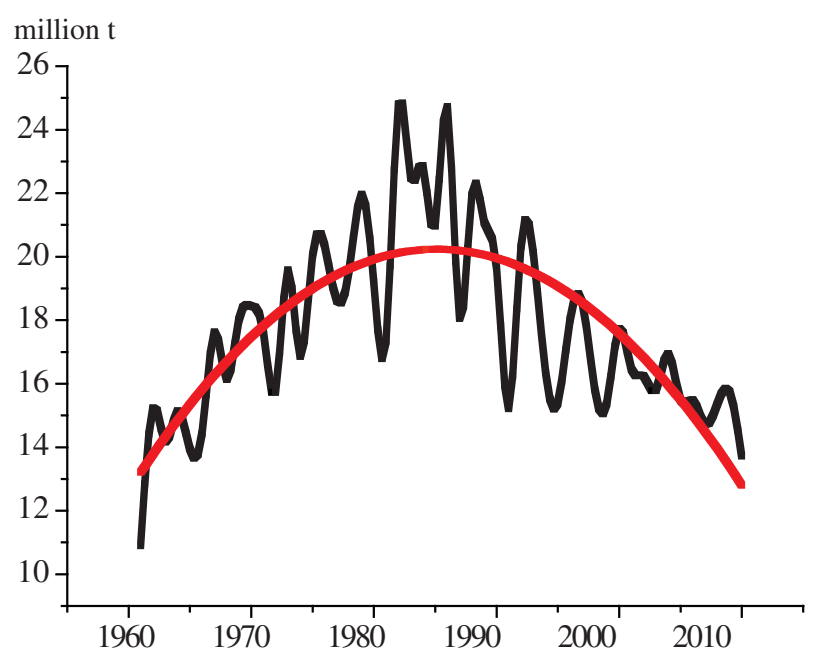

Fig. 2. Apple production in Europe

Source: own calculations, based on electronic database of FAO

At the same time, share of the Asian producers has increased from one tenth of the world production to nearly two third of production. The most important producer of apple is China, but there are considerable increasing of apple production in another emerging market economies, e.g. Turkey and Iran, too (Fig. 3).

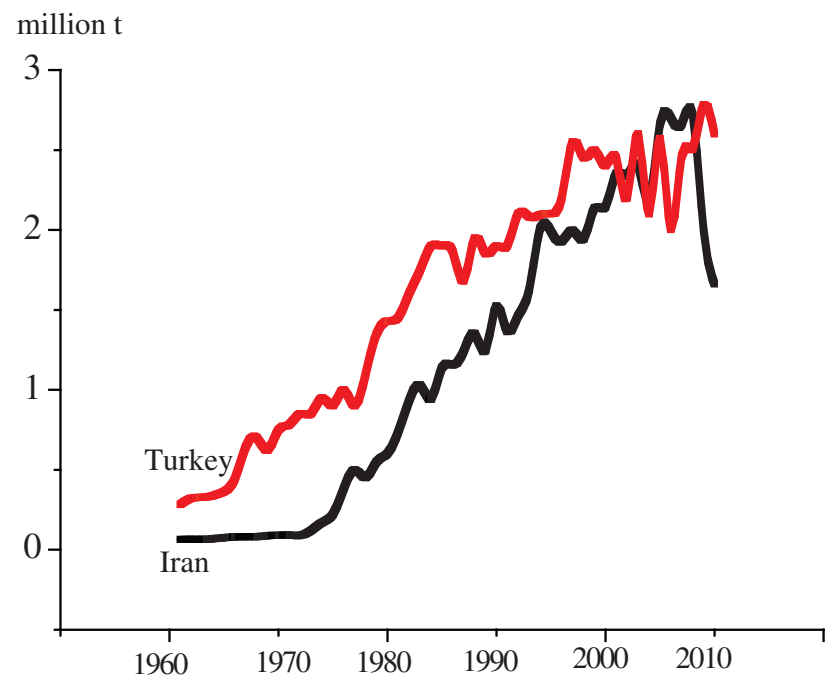

Fig. 3. Apple production of Iran and Turkey

Source: own calculations, based on electronic database of FAO 
According to a study of OECD (1991), accomplished in the early nineties (e.g. in "golden decade" of development) there is only a slow growth in demand for fresh apples in most developed market economies. This reflects the changing consumer preference for fresh fruits as the relative prices of non-traditional fresh fruits have declined. The estimates of the income $(0.1)$ and own price elasticity $(-0,1 \ldots-0,4)$ are low of demand for fresh apples are relatively low, compared to exotic fruits (e.g. oranges, banana) and to the products with lower consumption frequency and quality (e.g. pears).

Traditionally, the international apple trade had been categorised into three, relatively distinct markets: the export of fruits within the framework of Council for Mutual Economic Assistance has served mainly the apple-export from Hungary, Poland, Czech-Slovakia to the USSR. There were an important apple trade between the countries of the Northern Hemishpere and -mainly in off-season period-a considerable export from Southern Hemisphere towards the Northern Hemisphere. In last decades there emerged a considerable concentration process in the apple-trade: the most important fresh -product exporter is China, too. Nearly $80 \%$ of world apple export is run by ten states. It is extremely important, that among the ten most significant fresh apple exporters five countries are non-European, four of them situated in the Nordic Hemisphere.

As a summary of these market - processes it can be stated, that there is an increasing competition between the major apple-exporter countries. The most important means of this competition is the product - quality, price and reliability. That's why it is not enough to analyse the economic efficiency of apple production any more: the analysis should be augmented by a detailed analysis of the apple-production and storage system, too.

\section{Methodology}

Our research has been based on a comparative analysis of different models. These models have been developed on base of practical experiences of a wide range of active fruit producers and traders in North-Eastern part of Hungary, which traditionally is the most important region of apple production.

We have supposed the establishment of a relatively modern orchard. The aim of the grower is to establish a relatively high-quality apple production by a modern variety portfolio, with intensive production management. The most important characteristic features of the orchard: M9 tree rootstock, tall spindle system, $4 \mathrm{~m}$ distance between the rows, $1 \mathrm{~m}$ between the trees. The plant density is 2500 trees/ ha. As a consequence of the semi-arid climate, a sprinkling irrigation system is applied. Under Hungarian economic conditions there are not possibilities for the application of anti-hail net, that's why the expected value of production shows a relatively high fluctuations. We have calculated with a leg of 3 years between the apple tree planting and commercial yield. In our model the yield of the orchard increases rather rapidly over the next \# to \& years. Under intensive management the orchard achieves its production in th year. We have supposed a declining of production capacity of orchard from the th year of the plantation. This first model has ended in the phase of apple production. We have supposed a direct selling system of the products immediately after the harvest.

In second model we have applied a more sophisticated estimation. In this case the producer does not sell all of the apples on the market immediately after the harvest, but puts approximately $60 \%$ of the production into a cold storage facility. We have calculated with a high -quality Ultra Low Oxygen (ULO) facility.

The actual data, utilised in the calculations, have been based on our data-collection. The type and parameters of distribution of different economic values are based on estimation of local experts.

We have applied a cash-flow approach in the evaluation of the project. This means, that we have compared the in-and outflow of money into the project. That's why we had not have take the amortisation into consideration. Following the logic of cash-flow approach, the depreciation (amortisation) of physical infrastructure has not been taken into consideration). In our calculation, the cold storage facility is an For simplicity, we have calculated $25 \mathrm{t}$ cold storage capacity for an estimated yield of $40 \mathrm{t} / \mathrm{ha}$. According to our calculations, the difference between the yield and the cold storage capacity will be sold directly, without cold storage in autumn season. We have not taken into consideration the cost of machineries, too, because in our opinion these machines should be ready to the beginning of the fruit production.

In our calculations we have taken the time value of money into consideration, that's why we have discounted the future cash flows to the present value by the present value of cash flow formula:

$$
\mathrm{CF}_{\mathrm{d}}=\frac{\mathrm{CF}_{\mathrm{t}}}{(1+\mathrm{i})^{\mathrm{t}}}
$$

where:

$\mathrm{CF}_{\mathrm{i}}$ is the cash flow in the $\mathrm{n}_{\mathrm{th}}$ year;

$\mathrm{CF}_{\mathrm{d}}$ is the discounted value of cash flow;

$i$ is the discount rate (interest rate) at which the amount will be compounded each period;

$t$ is the number of period.

For the economic analysis of investment we have applied two indicators, the NPV and the IRR values. The net present value (NPV) can be defined as the "difference amount) between the sums of discounted cash in-and outflows. The form of calculation is as follows:

$$
N P V=\sum_{t=0}^{n} \frac{R_{t}}{(1+i) t}
$$

where

NPV - the net present value of the investment;

$t$ - the time of the cash flow;

$\mathrm{R}_{\mathrm{t}}$ - the net cash flow (the amoung of cash, inflow minus outflow) at time t. 
For the analysis two models were applied:

The internal rate of return (IRR) is a rate of return used in capital budgeting to measure and compare the profitability of investments (Nábrádi et al., 2009). This is practically the annualised effective compounded return rate. Practically, the IRR is the discount rate, at which the net present value of costs (negative cash flows) of the investment equals the net present value of the benefits (positive cash flows) of the capital investment. IRR can be used for the evaluation and comparison of capital investments in an specifically efficient way, because by its application can be evaluated the efficiency of the capital investment. The higher a project's internal rate of return, the more desirable it is to undertake the project.

The calculation are based on current Hungarian prices, not taking into consideration the inflation: put in another way: we have supposed that the enterprise is able to carry over the potentially negative (input price-increasing) effect of inflation to the buyers (e.g. wholesale-traders).

It was an important question, how to determine the level of time-preference. For the choice of the optimal rate of time -preference there are no clear-cut rules. If the timepreference is too high, the cash -flows, emerging at a later time horizon, loss their importance, if this value is too low, the importance of cash flow of first years (in general, this is the period of investment) is under-estimated. There are different approximations of applied discount rates (Table 1).

In opinion of Rambaud and Torrecillas (2006) if the project is ingra-generational (does not have impact beyond 50 years) and 3,5\% of discount rate should be applied.

Table 1. Different estimations of time-preference value

\begin{tabular}{|l|c|}
\hline Commissariat Général du Plan (2000) & $8 \%$ \\
\hline Commissariat Général du Plan (2004) & $4 \%$ \\
\hline $\begin{array}{l}\text { Conferenza dei Presidenti delle Regioni e delle Province } \\
\text { Autonome (2001) }\end{array}$ & $5 \%$ \\
\hline European Comission (for water resource project management) & $4 \%$ \\
\hline European Commission (2001) & $5 \%$ \\
\hline Her Majesty Treasury (1997) & $6 \%$ \\
\hline Her Majesty Treasury (2003) & $3,5 \%$ \\
\hline Ministerio de Transportes, Turismo y comunicaciones (1991) & $6 \%$ \\
\hline
\end{tabular}

Source: Own compilation, based on Rambaud and TOrrecillas, 2006
The basic data of the two models are summarised in Tables 2 and 3 .

The basic assumptions of the cash-flow tables were as follows:

- we have tried to separate the fix and variable costs of production;

- in case of variable costs, we have assumed a linear relationship between the production quantity and the costs of production;

- we have assumed a constant expected value of product price. This can be challenged, because as a consequence of the globalising competition a cost decreasing could be-theoretically- expected;

In first model we have not taken into consideration the costs of small containers. In second one we have involved this cost into the start-up cost of the cool storage facility.

Based on expert estimations, we have expected a lesser value of standard deviation in case of price of stored apples, than in case of apples, sold immediately after the harvest, in September.

In case of cool storage model we have calculated with this cost-factor, because it can be considerably influence the cost of production.

We have not taken into consideration the effect of the opportunity cost in production phase, because this would be a highly speculative calculation. At the same time, we have considered the opportunity cost in case of inventory finance of cool storage. In our logic, if the enterprise sell its apple directly after the harvest, it realises the price immediately. If the selling of inventory takes place in May, it means, that the income will be realised much later. The cost of capital employed has been estimated by the yield of Hungarian treasury bill. Based on a conservative approach, we have estimated a 4 per cent yield of this treasury bill for the period of storage.

The investment analysis has been carried out by @Risk software, following the procedure, described in our former communication (Lakner and Márkusz, 2007).

Table 2. Base data of the apple-production model without cold storage

\begin{tabular}{|c|c|c|c|c|c|c|c|}
\hline \multirow{2}{*}{ Indicator } & \multicolumn{7}{|c|}{ Year } \\
\hline & 1 & 2 & 3 & 4 & $5-13$ & 14 & 15 \\
\hline Yield (t) & 0 & 10 & 25 & 35 & 40 & 30 & 25 \\
\hline standard deviatinon of yied $(\mathrm{t})$ & 0 & 4 & 5 & 6 & 8 & 10 & 11 \\
\hline Price $(\mathrm{Ft} / \mathrm{kg})$ & 50 & 50 & 50 & 50 & 50 & 50 & 50 \\
\hline standard deviation of price $(\mathrm{Ft} / \mathrm{kg})$ & 15 & 15 & 15 & 15 & 15 & 15 & 15 \\
\hline Fixed costs $(\mathrm{Ft} / \mathrm{ha})$ & 4800 & 250 & 400 & 700 & 830 & 830 & 830 \\
\hline Standard deviation of fixed costs (Ft/ha) & 480 & 25 & 40 & 70 & 83 & 83 & 83 \\
\hline Vaiable costs $(\mathrm{Ft} / \mathrm{kg})$ & 5,5 & & & & & & \\
\hline Standard deviation of variable costs $(\mathrm{Ft} / \mathrm{ha}$ & 1,65 & 1,65 & 1,65 & 1,65 & 1,65 & 1,65 & 1,65 \\
\hline
\end{tabular}


Table 3. Base data of the apple-production and cold storage model

\begin{tabular}{|c|c|c|c|c|c|c|c|}
\hline \multirow{2}{*}{ Indicator } & \multicolumn{7}{|c|}{ Years } \\
\hline & 1 & 2 & 3 & 4 & $5-13$ & 14 & 15 \\
\hline $\begin{array}{l}\text { Investment of cool storage device for } 1 \text { ha produciton } \\
\text { surface ( } 350 \text { thousand } \mathrm{Ft} / \mathrm{t} \text { apple) }\end{array}$ & & & & 12000 & & & \\
\hline Variable costs of cool storage $(\mathrm{Ft} / \mathrm{kg})$ & & & & 4 & 4 & 4 & 4 \\
\hline Standard deviation of varible costs $(\mathrm{Ft} / \mathrm{kg})$ & & & & 1 & 1 & 1 & 1 \\
\hline $\begin{array}{l}\text { Fixed costs of cool storage for } 1 \text { ha production surface } \\
\text { (thousand } \mathrm{Ft} \text { ) }\end{array}$ & & & & 52 & 52 & 52 & 52 \\
\hline Products sold in direct selling $(\mathrm{t})$ & 0 & 10 & 25 & 35 & 14 & 10,5 & 8,75 \\
\hline Products sold after cool storage & & & & & 26 & 19,5 & 16,25 \\
\hline $\begin{array}{l}\text { Opportunity costs of inventory finance from October to } \\
\text { May }(\%)\end{array}$ & & & & & 0,04 & 0,04 & 0,04 \\
\hline $\begin{array}{l}\text { Standard deviation of inventory finance from October to } \\
\text { May }(\%)\end{array}$ & & & & & 0,02 & 0,02 & 0,02 \\
\hline Standard deviation of price in May $(\mathrm{Ft} / \mathrm{kg})$ & & & & & 12 & 12 & 12 \\
\hline
\end{tabular}

\section{Discussion}

Analysing the results of simulation of the first model (apple growing without cold storage) it is obvious, that the value of internal rate of return is relatively high. It means, that the income-generating capacity of the project is well beyond the average of the market. This fact can be explained by the relatively low investment costs. At the same time it should be taken into consideration, that the standard deviation of the distribution is relatively large. The $90 \%$ of IRR values falls between $5,3 \%$ and $21 \%$ (Fig. 4).

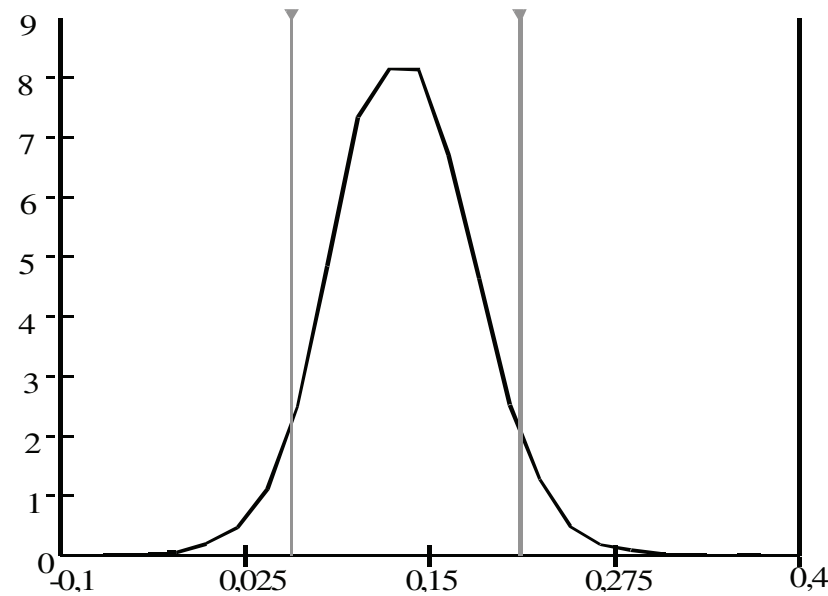

Fig. 4. The density function of internal rate of return in case of apple growing investment

The sensitivity of the IRR values can be quantified by the regression analysis of the input values and the IRR of the model. In this method it can be stated, that the highest influence on the value of internal rate of return exercise the cost of investment in the first year, and the product-prices in different years.

The expected value of NPV of investment is 3716 thousand Ft, which can be considered as a relatively low one (Fig. 5). The standard deviation is a high one: the $90 \%$ of values will fall between 738 and 6891 thousand Ft. The NPV

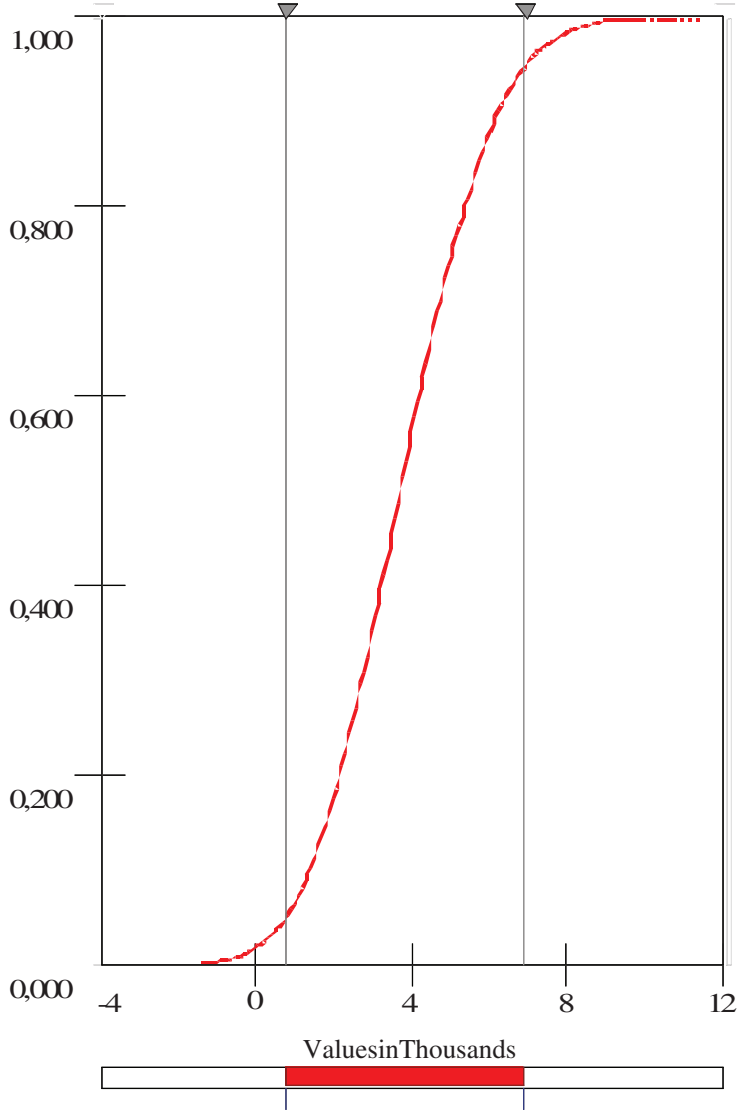

Fig. 5. The distribution function of net present value

is more sensitive to prices than to cost of investment, but the relative influence of product-prices in different years is lower, than in case of IRR. The value of regression between the individual prices and the NPV is relatively low, it is hard to choose one or some well-determined year, which could considerably info

If we do not take the opportunity cost of inventory finance into consideration, than the IRR value is around one per cent, the NPV value negative, -2105 thousand Ft (Fig. 6). If we 


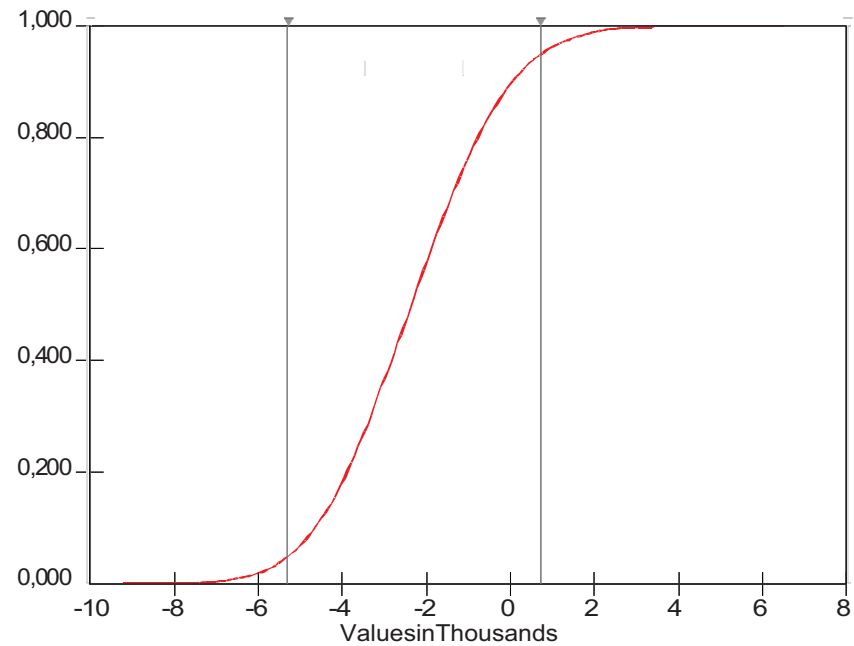

Fig. 6. The distribution function of net present value of apple growing-cool storage system, without state support

take the inventory finance into consideration, there is no any positive internal rate of return. The most important influencing factor is the high investment cost of the establishment of cooling facility. This cost per hectare is approximately two and a half times higher, than the costs of establishment a new plantation. That's why there is a necessity of supporting the establishment of cooling facilities.

The feasibility of the cool storage investment could be considerably improved by a state support for the investment of the cool storage facility. In case of a 50\% support for storage investment, a $8 \%$ IRR could be achieved. At the same time it should be taken into consideration, that there is a considerable cost-decreasing with increasing the size of the storage facility. That's why the establishment of storagecooperatives should be promoted.

\section{Acknowledgement}

Research was sponsored by TECH_08-A3/2-2008-0373 grant.

\section{References}

http://faostat3.fao.org/home/index.html\#DOWNLOAD (last accessed: 12.06.2012)

Lakner Z. \& Márkusz P. (2007): Feasibility of investments in hungarian grapewine sector. International Journal of Horticultural Science, 14 (1): 37-42.

OECD (1991): The apple market in OECD countries, OECD/ OCDE, Paris, 134.

Nábrádi, A., Pető, K., Balogh, V., Szabó, E., Bartha A. \& Kovács, K. (2009): Efficiency indicators in different dimension, APSTRACTApplied studies in agribusiness and commerce, 3 (1-2): 7-22.

Rambaud, S.C. \& Torrecillas, M.J.M. (2006): Social discount rate: a revision. Anales de Estudion Economicos y Empresariales, 46 (1): 75-98.

Takács-György, K. \& Vágány, J. (2003): The effects of changing food quality requirements on Hungarian food producing farms. Acta Horticulturae, 604 (2): 467-472. 